\title{
Biografias improváveis: o si mesmo de um outro como imaginação historiadora ${ }^{1}$
}

\begin{abstract}
Marialva Carlos BARBOSA ${ }^{2}$
Resumo:

A ausência de autobiografias dos escravizados no Brasil é o ponto de partida para a reflexão que introduz a possibilidade de escrever sobre suas vidas passadas usando também a imaginação na produção de uma escritura que de ausente se transforme em presença. Os modos de comunicação, a produção de diálogos com os tempos idos, a percepção de vidas duplamente excluídas no passado e no futuro, e, sobretudo, a premissa da reconstrução do biográfico/autobiográfico pela produção de vínculos, permitem o exercício de reconstruir vidas passadas cujas vozes foram duplamente silenciadas: no seu tempo e no futuro/presente. Estamos propondo, assim, a reescrita de vidas a partir de modos de comunicação produzidos no passado por estes agentes da história, mas cujo registro de suas vozes nem sempre estiveram presentes. Biografias de escravizados como imaginação historiadora.
\end{abstract}

Palavras-chave: biografias; escravizados; história; comunicação.

\section{Unlikely biographies: another's self as historian imagination}

\begin{abstract}
:
The absence of autobiographies of the enslaved in Brazil will be the starting point for the reflection that introduces the possibility of writing about their past lives, also using imagination in the production of a writing that transforms from absence into presence. The modes of communication, the production of dialogues with times gone by, the perception of lives doubly excluded in the past and the future, and, above all, the premise of reconstructing the biographical/autobiographical through the production of links, allows the exercise of reconstructing past lives whose voices were doubly silenced: in their time and in the future/present. Thus, we are proposing the rewriting of lives based on modes of communication produced in the past by these agents of history, but whose recording of their voices was not always present. Biographies of Enslaved as Historian Imagination.
\end{abstract}

Keywords: biographies; slaves; history; communication.

\section{Biografías inverosímiles: el yo de otro como imaginación del historiador}

\section{Resumen:}

La ausencia de autobiografías de los esclavizados en Brasil será el punto de partida para la reflexión que introduce la posibilidad de escribir sobre sus vidas pasadas, utilizando también la imaginación en la producción de una escritura que se transforma de la ausencia en presencia. Los modos de comunicación, la producción de diálogos

\footnotetext{
${ }^{1}$ Palestra realizada no XIII Encontro Nacional de História da Mídia, 18 a 20 ago. 2021, UFJF, Juiz de Fora, MG, Brasil.

${ }^{2}$ Doutora (1996) em História, pela Universidade Federal Fluminense (UFF), com pós-doutorado em Comunicação (1999), pelo Centre National des Recherches Scientifiques (LAIOS-CNRS), em Paris-França. Professora Titular de Jornalismo, da Universidade Federal do Rio de Janeiro (UFRJ) e docente aposentada da Universidade Federal Fluminense.E-mail: marialva153@gmail.com
} 
con tiempos pasados, la percepción de vidas doblemente excluidas en el pasado y el futuro y, sobre todo, la premisa de reconstruir lo biográfico / autobiográfico a través de la producción de vínculos, permiten el ejercicio de la reconstruyendo vidas pasadas cuyas voces fueron doblemente silenciadas: en su tiempo y en el futuro / presente. Así, proponemos la reescritura de vidas a partir de modos de comunicación producidos en el pasado por estos agentes de la historia, pero cuya grabación de sus voces no siempre estuvo presente. Biografías de esclavizados como historiador imaginación.

Palabras clave: biografías; esclavizados; historia; comunicación.

\section{Introdução}

Ainda que existam, há décadas, diversas biografias dos escravizados, constituindo-se num amplo movimento da história, sobretudo nos países de língua inglesa, que se amplia pela tradição dos estudos literários norte-americanos, por exemplo, em torno da North American Slave Narratives, ${ }^{3}$ no Brasil, exceto a autobiografia de Mohommah Baquaqua (2017), ${ }^{4}$ são escassas as narrativas de vida desses homens e mulheres.

Essa ausência atesta o movimento de incluí-los no lugar de não produtores de vozes audíveis, encobrindo seus modos de vida, e, por caminhos múltiplos, há o esforço de construir, também pelo apagamento do comunicacional, esquecimentos duradouros. Suas vidas cotidianas, nas quais emergiam complexos modos comunicacionais, seja nos territórios da oralidade, seja nos territórios da leitura e da escrita - através dos quais também se produziam como si-mesmos - são elevadas à condição de conhecimento maldito, coisa que ninguém precisa saber (HELLER, 1993). E, assim, ficam sob o domínio do silêncio, até que um historiador, ao estabelecer uma franca e prolongada conversa com os mortos, resolva dar eco às vozes que foram sistematicamente apagadas. Foi isso o que tentei fazer quando escrevi, em 2016, um livro sobre os modos de comunicação dos escravizados brasileiros no século XIX, ornados pelos territórios e suas competências nesses domínios, em busca dos modos complexos comunicacionais que escreveram e inscreveram suas vidas do passado em direção ao futuro (BARBOSA, 2016).

\footnotetext{
${ }^{3}$ As Slave Narratives têm longa tradição na literatura norte-americana, começando a ser publicadas a partir de fins do século XVIII, aumentando e disseminando-se ao longo do século XIX no mundo anglofônico. Foram também fontes utilizadas por historiadores norte-americanos. Referências importantes sobre autobiografias de escravizados nos Estados Unidos, segundo Alexandra Silva (2018), são Blassingame (1977), Gates (1985), Rawick (1972), Starling (1949) e Yetman (1984). Sobre biografias de escravizados, ver também Alexandra Silva (2018) e Pirola (2015).

${ }^{4}$ Sobre a autobiografia de Mohommah Gardo Baquaqua, cf. Lovejoy (2002).
} 
Nos últimos anos, diversos pesquisadores vêm construindo trilhas para permitir a reconstrução das trajetórias de vida desses homens e mulheres a partir de relatos em primeira pessoa, ainda que recuperados em outros dispositivos: cartas, petições, testamentos, processos penais, entre diversas outras ordens documentais que permitem reconstruir trajetórias de vida. ${ }^{5}$

Destacando a heterogeneidade de linhas teóricas desses estudos, Pirola (2015) enfatiza que, inspirados em métodos indiciários (GINZBURG, 1987) e em outros que fazem da redução da escala de análise e na pesquisa em fontes seriais as abordagens empíricas dominantes, debruçando-se nos arquivos regionais, documentos cartoriais (inventários e testamentos), judiciários (processos-crimes e processos civis), utilizam, muitas vezes, como inspiração os trabalhos de Davis $(1987,1997)$.

O que este artigo propõe é de outra ordem. Partimos do pressuposto de que, desarticulando fatos conhecidos e permanentemente reinterpretados, a história pode ser pensada como o "poderia ter sido" da vida dos homens inscritos no passado. Assim, relacionando o verossímil que o documento apresenta com infinitas doses imaginativas, nos propomos a escrever a história de vida (imaginando existências) de homens e mulheres que foram colocados no lugar da subalternidade absoluta, mas que, ao terem resgatadas no futuro suas vozes, seus gestos, seus medos, suas emoções, provam ao infinito que vidas negras, de fato, importam. No presente e do passado até o presente.

O gesto de como um outro tentar construir o si mesmo dos escravizados tem como propósito permitir a eles reescreverem suas próprias vidas, como possibilidade, fazendo emergir, a partir de altas doses de imaginação, o passado como outro possível do futuro. Abremse, assim, para esses homens e mulheres trilhas do provável, numa história que permite novas e imaginativas articulações narrativas.

Dividimos o artigo em duas partes. Na primeira faremos breves considerações sobre o biográfico e o autobiográfico, vasto terreno da expressão de um eu, aqui denominado, a partir da inspiração em Ricoeur (1996), o si mesmo como um outro possível, em que cada escravizado será pensado como sujeito a partir da sua outridade, ou seja, do contexto dialógico em que se

\footnotetext{
${ }^{5}$ Regina Xavier (2000) indica os relatos orais como possibilidade de recuperar vozes autobiográficas dos escravizados, citando os estudos de Eduardo Silva (1997), sobre D. Obá II D’África; ou de Reis (2008), sobre o sacerdote africano Domingos Sodré; e as pesquisas de Azevedo (1999), sobre Luiz Gama. Pirola (2015) cita também Furtado (2003); Frank (2004); Graham (2005); Reis (2008); Xavier (2008); Reis, Gomes e Carvalho (2010); Machado (2010) e Sweet (2011).
} 
dá o seu discurso (BAKHTIN, 1982). Recuperar e escrever biografias improváveis também constrói sentidos para discursos do presente, tempo em que se clama por vidas negras que importam.

Considera-se que não há coincidência entre autor e personagem, nem mesmo quando a produção se constitui como autobiografia, uma vez que a personagem central da trama se expressa sempre pelo discurso a outro que se constitui por meio dele. Neste sentido, a proposta é construir um outro dialógico, um autobiográfico construído a partir da certeza de que existe um espaço de reconhecimento para essas vozes. É deste diálogo que surge, então, nesgas fulgurantes de imaginação sobre vidas que existiram e pelo gesto narrativo continuam existindo e tendo existência.

Chegamos, então, à segunda fase do texto, em que apresentaremos o experimento biográfico como biografias improváveis. Para isso, propomos a recuperação da vida, das emoções, do cotidiano e dos gestos do "Escravo Severo", tal como ele apareceu nominado no jornal Gazeta de Notícias, quando anunciou seu crime. Severo permaneceu existindo como possibilidade de ter sua vida reconstruída, a partir da imaginação histórica, mas também se valendo dos indícios do passado fixados nos documentos, cujo ponto de partida foi uma notícia publicada na primeira página do jornal, em 14 de outubro de 1884. Esse exercício escriturário em que propomos construir biografias históricas ${ }^{6}$ é o primeiro de uma série de olhares lançados a essas vidas passadas à procura de vozes audíveis, situadas, ainda hoje, como vozes emudecidas. $^{7}$

Mas porque biografias improváveis? A primeira e mais evidente razão refere-se ao fato de ser absolutamente impossível provar a existência de um único passado, já que este está sempre submetido a regimes de possibilidades, nos quais o ato interpretativo configura o ato

\footnotetext{
${ }^{6}$ Sacramento (2012), ao escrever a biografia de Dias Gomes, realiza um exercício criativo, mostrando as articulações entre o individual e o social na construção do dramaturgo como figura pública. Para isso, propõe a biografia comunicacional, na qual o foco desloca-se da atividade individual para o circuito comunicativo das produções discursivas que conformam o indivíduo e se aglutinam em torno dele. Considerando a comunicação como a vinculação entre o eu e outro (SODRÉ, 2014), emerge dessas biografias tanto o si genérico, como o si mesmo singular, mediado pela transcendência do outro, já que há sempre outros que habitam o si mesmo nos processos de vida desenvolvidos como vínculos comunicacionais.

${ }^{7}$ Este texto faz parte de uma pesquisa maior cujo objetivo é realizar biografias improváveis de pelo menos quatro escravizados. Há diversos exemplos de estudos históricos que buscam recuperar e reescrever trajetórias de escravizados, percebendo na singularidade de personagens questões que diziam respeito às suas vidas e ao seu mundo. Citamos particularmente o belo artigo de Sandra L. Graham (2012) e Alexandra Silva (2018); Machado (2010); Farias (2012, 2013); Moreira (2020) e Góes e Florentino (2016).
} 
imaginativo, enxertando nos rastros deixados probabilidades e nunca provas indeléveis. A segunda diz respeito ao improvável como dúvida. A imaginação histórica pressupõe a reconstrução em fímbrias de cenas pelas imagens materializadas por aquele que é o autor final da narrativa. Documentos inexistentes, relações figuradas com o real abrem brechas ao improvável enquanto dúvida e lugar de construção dos laços comunicacionais. Do passado até o presente produzidos também pela imaginação. Mas a imaginação do passado aciona no pesquisador historiador a busca pelo provável: a aparência das ruas, as casas da época, o trem que passava, o bonde que sacolejava, a rua repleta de gente no centro da cidade. Barulhos, cheiros, cores, visões, os sentidos vão permeando a vida e transformando-a na documentação possível de uma época. Os traços que o passado deixou, restos de um tempo transformados em rastros (RICOEUR, 2008), permitem construir um provável que, no caso que apresentamos no texto, será sempre da ordem do imaginável.

\section{A vida como história: algumas considerações sobre o biográfico}

O que produz as diferenças e as semelhanças entre o biográfico e o autobiográfico? Poderíamos marcar a diferença a partir de quem toma a palavra. A autobiografia seria, então, aquela que expressaria um nome próprio, em que haveria uma coincidência empírica entre o eu que narra e aquilo que é narrado. Mas se considerarmos que não existe a possibilidade dessa consciência, já que o narrador ao assumir esse papel será sempre um outro, diferente daquele que protagonizou o que vai narrar, autobiografias e biografias inserem-se na mesma cadeia narrativa das escritas produzidas por biógrafos, seja ele um outro ou um outro eu.

Ao construir a noção de espaço biográfico como dialógico, Arfuch amplia a noção de Lejeune (2008), como "reservatório das formas diversas em que as vidas se narram e circulam", que, segundo ela, não seria suficiente para delinear um campo conceitual (ARFUCH, 2010, p. 57). O espaço autobiográfico de Lejeune se constituiria de um conjunto de escritos que reflete, com diversos graus de invenção e busca pela verdade, a imagem, ao mesmo tempo múltipla, fragmentária e lacunar, que um escritor oferece de si mesmo aos seus leitores (LEJEUNE, 2008). A construção desse espaço pressupõe um pacto evidente com o leitor, no qual a autobiografia seria um tipo específico de texto e um conjunto de práticas de caráter variado, construindo o vasto terrento da expressão do eu. Nela estariam incluídos, como critérios 
definidores, o pacto de verdade, o relato retrospectivo em primeira pessoa do singular, a identidade nominal entre autor, narrador e personagem.

A emergência de novas formas contemporâneas autobiográficas (cinema, artes plásticas, entrevistas, narratividades das redes sociais e outras revelando existências virtuais) que se acoplam às tradicionais maneiras de narrar a própria vida - memórias, correspondências, diários íntimos etc. - mostra a urgência de ultrapassar o par biográfico/autobiográfico na direção do reconhecimento de um espaço biográfico, no qual formas de discursos genéricas e múltiplas estratégias de autorrepresentação passam a ser construídas.

É assim que Arfuch (2010, p. 57) propõe pensar o espaço biográfico partindo da proposta de "relações, em presença e ausência, entre formas com grau diverso de proximidade, relações nem necessárias nem hierárquicas, mas que adquirem seu sentido precisamente num espaço/temporização, numa simultaneidade de ocorrências”. O espaço biográfico, como "confluência de múltiplas formas, gêneros e horizonte de expectativa", permite considerar "as especificidades respectivas sem perder de vista sua dimensão relacional, sua interatividade temática e pragmática, seus usos nas diferentes esferas da comunicação e da ação" (ARFUCH, 2010, p. 57-58). E propõe estudar a "circulação narrativa das vidas" em múltiplos suportes comunicacionais, em que restos de um si mesmo vão construindo a dimensão pública/privada de uma vida exposta cotidianamente, que, com o avanço da midiatização na contemporaneidade, multiplicam-se ao infinito (ARFUCH, 2010, p. 58).

Arfuch $(2010$, p. 62) remarca que o conceito não constrói equivalência ou indistinção entre gêneros e formas não similares, mas permite a inclusão de narrativas vivenciais que abarcam múltiplos registros, numa "trama de interações, hibridizações, empréstimos e contaminações", apresentando o biográfico numa multiplicidade de relatos, "romances, ensaios, investigações”, e, acrescentaríamos, documentações várias das vidas inscritas em diferentes épocas (processos penais, fichas de identificação, documentos administrativos, informações publicadas na imprensa, entre muitas possibilidades). Afinal, todos os discursos presentes no mundo tecem a ação humana (BAKHTIN, 1997). E nessas teias narrativas, vidas se deixam ver, ser olhadas, para poderem ser lembradas e narradas.

Pensando o gênero discursivo a partir da perspectiva de Bakhtin (1997), ao conceituar espaço biográfico, Arfuch (2010, p. 66) destaca não apenas as constantes misturas e 
hibridizações discursivas, mas a lógica dialógica da comunicação, em que o outro já faz parte do meu enunciado, uma vez que a linguagem é sempre habitada por vozes que deixam rastros ao longo dos séculos: "uma palavra alheia que expressa sentidos, tradições, verdades, crenças, visões do mundo, e que o sujeito assume de forma natural", apropriando-se pelos usos que dela fizer, pelos gêneros discursivos elencados e, sobretudo, "pelas tonalidades de sua afetividade" .

$\mathrm{Na}$ ideia dialógica da comunicação não existe a primazia do enunciador, uma vez que este já está determinado por um outro. Há, portanto, simultaneidade na atividade dos que dela participam, interação em presença, atravessada pela escrita que emoldura os gêneros escriturários. Assim, tanto o enunciador como o destinatário são outros, suportes destas múltiplas vozes que constituem os discursos sempre relacionais, produzindo significações intertextuais. A obra, para Bakhtin (1997), é sempre a réplica de um diálogo e se relaciona a outras obras-enunciados.

O biográfico, ao ordenar vidas para serem apropriadas, produzindo modelos e laços, garante que aquela vida existiu, conferindo sua certificação, pela emergência do eu, do nome próprio, não apenas escrito, mas inscrito, atestando a presença. Se acrescentarmos o efeito testemunho, que advém daquele que guarda a existência na carne e na alma, há a eclosão do revelado por vozes únicas. No caso das biografias improváveis, a ancoragem numa real suposição do realizado no passado confere fidelidade possível às vidas que não deixaram suas próprias falas na situação de audíveis. O testemunho indireto advém do espaço partilhado, em comum, de uma presunção de passado reconhecido, trazido novamente à luz, pela reconstrução de cenas que, do plausível, transformam-se em possível.

Portanto, o que importa na construção do biográfico improvável não é, tal como em qualquer enunciado biográfico, a adequação aos acontecimentos de uma vida ao conteúdo do que foi efetivamente aquela vida (acontecimentos, momentos, atitudes), mas as estratégias, sempre ficcionais, de qualquer auto representação (ARFUCH, 2010). Não é a verdade do ocorrido, mas sua construção narrativa, “os modos de nomear no relato, o vaivém da vivência ou da lembrança, o ponto do olhar, o que se deixa na sombra; em última instância, que história (qual delas) alguém conta de si mesmo ou de outro eu" (ARFUCH, 2010, p. 71).

No caso, deliberadamente estamos assumindo o papel do outro eu - mesmo sem outorga - para reapresentar vidas, buscando o fazer crer não de um discurso que, ainda que existente no 
passado, não se tornou audível no futuro, mas procurando na existência verificável do próprio passado a possibilidade de transformar documentos em marcas enunciativas e retóricas que atestariam essas vidas. A partir desse exercício é preciso deixá-los falar. Buscar a plenitude da presença desses personagens por meio de seus gestos, de suas faces e do eco de suas vozes. Enfim, inserir vidas no espaço biográfico, transformando-as de perdidas em reconhecidas. Afinal, a narrativa vivencial pressupõe como gesto primeiro imaginar vidas.

\section{Restaurando vidas: o passado como poderia ter sido}

Havia um homem chamado Severo. Tinha apenas 20 anos e era solteiro. Embora qualificado como "trabalhador da roça", na sequência da informação sobre o seu analfabetismo, vivia, junto com o irmão, numa casa na rua do Engenho de Dentro, na freguesia do Engenho Novo, no Rio de Janeiro. ${ }^{8}$ A rua do Engenho de Dentro ficava bem perto da linha férrea e da estação de mesmo nome. Precisamente, do lado oposto às Oficinas da Estrada de Ferro Dom Pedro II, inauguradas em 1871, e que trouxeram expressivo crescimento para a região. ${ }^{9}$

De casa, certamente Severo ouvia passar, de tempos em tempos, na estação, trens, produzindo ruídos. Apitos, paradas, estancadas, pessoas falando, coches passando, animais pastando, uma infinidade de sons num lugar em que a vida urbana começava a se fazer pulsante. Bem perto dali uma praça, onde os primeiros bondes da Companhia Ferro-Carril Vila Isabel, que chegaram ao lugar em março de 1872, faziam parada final até o próximo retorno.

Uma casa, "pintada e forrada de novo, com duas salas, saleta, quartos, cozinha, muito terreno com árvores de fruto, linda vista e lugar salubérrimo" (GAZETA DE NOTÍCIAS, 6 jun. 1883 , p. 3). Talvez fosse assim a casa em que Severo morava, tal como descreviam os anúncios dos jornais que ofereciam residências na mesma rua em meados de 1883. No quintal, certamente

\footnotetext{
${ }^{8}$ As informações que apresentam de Severo foram retiradas das notícias publicadas nos jornais, do crime ao seu julgamento. Gazeta de Notícias, 24 jul. 1883, p. 1; Gazeta de Notícias, 14 out. 1884, p. 1; O Paiz, 14 out. 1884, p. 2; Gazeta de Notícias, 11 out. 1884, p. 2; O Paiz, 14 out. 1884, p. 2.

${ }^{9}$ Para a caracterização do Engenho Novo nos valemos de diversas fontes: Recenseamento do Rio de Janeiro de 1906, 1907, p. 13; Almanak Administrativo, Mercantil e Industrial da Corte e da Província do Rio de Janeiro, 1875; Jornal do Commercio, 19 abr. 1878, p. 1; Diário de Notícias, 2 jun. 1886, p. 2; Gazeta Suburbana, 15 dez. 1883, p. 1; Planta da cidade do Rio de Janeiro, 1900; Gazeta de Notícias, 9 jan. 1880, p. 5; Gazeta de Notícias, 26 fev. 1880, p. 1; Gazeta de Notícias, 1 fev. 1883; Gazeta de Notícias, 24 fev. 1883, p. 1; Gazeta de Notícias, 6 jun. 1883, p. 3; Gazeta de Notícias, 4 nov. 1883, p. 2; Gazeta de Notícias, 1 mar. 1884, p. 2. Como fonte secundária usamos, sobretudo, Serfaty (2017).
} 
pés de laranjeiras dividiam espaço com mangueiras e outras frutas que traziam sombra e barulho de sons vibrando nos galhos e folhas das árvores quando o vento se fazia mais forte.

A vida de Severo se repetia igual todos os dias. Acordava cedo, era obrigado a fazer vários serviços na casa, sempre com hora marcada, ordem programada, sem possibilidade de recusa. Mas aquele dia seria diferente.

O final da tarde fazia pressentir a noite. Severo tinha acabado seu serviço diário e se preparava para descansar. Veio então a ordem: que fosse socar um pouco de café. Severo se recusou e dirigiu a Rosinda Lucinda Fernandes ${ }^{10}$ palavras que foram qualificadas como "menos convenientes". Com raiva, Rosinda "deu-lhe com um bambu algumas pancadas". Severo calouse e dirigiu-se a seu quarto. Poucos instantes depois, seu irmão a abordou nervoso, pedindo que ela se escondesse, "porque Severo estava carregando a espingarda para matá-la".

Severo era o Escravo Severo, que naquele dia 22 de julho de 1883 se revoltou contra mais uma ordem, contra mais uma pancada e reagiu. O que aconteceu com Severo? De fato, ele carregou sua espingarda, saiu furioso para o quintal, subiu no telhado para arrancar as telhas e lá do alto descarregar a arma contra Rosinda. Uma fúria insana que encobria anos de cativeiro, palavras injuriosas, gestos infames.

Quando escutou o barulho das telhas sendo arrancadas, Rosinda correu para o quintal, mas, ao abrir a porta, lá estava Severo que desfechou contra ela a arma, ferindo-a nas pernas. "Estes fatos deram-se das 7 às 9 horas da noite, na casa da residência da vítima, a rua do Engenho de Dentro, na freguesia do Engenho Novo", escreveu o jornalista anônimo na notícia publicada na primeira página da Gazeta de Notícias em 14 de outubro de 1884.

A notícia descrevendo com detalhes o "Crime do Escravo Severo" só seria publicada mais de um ano depois, quando do anúncio do seu julgamento. $\mathrm{Na}$ época do "crime", uma lacônica nota, sob a rubrica "Ocorrências das ruas" na Gazeta de Notícias (24 jul. 1883, p. 1), informava:

Anteontem, às 7 horas da noite, foi ferida na coxa direita com um tiro de espingarda, Rosinda Lucinda Fernandes, moradora no lugar denominado Engenho de Dentro, por um seu escravo de nome Severo, que em seguida se evadiu, indo refugiar-se nos matos próximos ao lugar do delito. A autoridade

\footnotetext{
${ }^{10}$ O nome aparece com várias grafias nos diversos documentos: Rosina, Rosinda Lucina, Rosina Lucina e Rosinda Lucinda. Unificamos todas as grafias como Rosinda Lucinda
} 
local, teve os matos cercados até ontem pela manhã, não conseguindo prender o criminoso.

Seguindo as pistas deixadas pela notícia, ficamos sabendo que Severo, após ter ferido Rosinda, passara dois dias escondido nos matos. Conhecia certamente muitos caminhos intransponíveis. Apesar de os loteamentos no bairro terem começado no início da década de 1870, dez anos depois, mesmo com as muitas edificações já existentes nas principais ruas, entre as quais a do Engenho de Dentro, onde casas térreas dividiam espaços com chalés, lojas e sobrados, ${ }^{11}$ havia ainda no entorno espaços possíveis de serem transformados em esconderijos.

A vida de Severo, do Escravo Severo, só pode ser remontada a partir do que estamos denominando o "poderia ter sido" do passado, que permite na sanha reconstrutora de um tempo que não mais existe imaginar cenas, reconstruir cenários, escutar sons, ver gestos e buscar em elementos esparsos a expressão da vida vivida de personagens anônimos. Como personagem anônimo, também Severo não deixou uma vida registrada em traços guardados nos arquivos ou gestos de sua fala imortalizados em nuances comunicacionais. Tudo o que sobrou foram notícias caracterizando-o como facínora, cínico, mal-agradecido, já que tinha sido sempre "tratado com carinho" por sua senhora. Mas o gesto e a fúria de Severo provam o contrário.

Dois dias foi o tempo em que Severo ficou escondido "nos matos". Só em 24 de julho foi capturado. Depois de desfechar o tiro contra Rosinda, podemos supor, Severo correu pela estrada de terra em busca de um canto escuro para se abrigar. Certamente teve frio, afinal, era julho. Certamente teve fome. Certamente estava com raiva, certamente teve medo, certamente não sabia muito bem o que fazer.

Do esconderijo, escutava os sons, os barulhos das ruas e talvez música que ecoava ao longe. Afinal havia na rua do Engenho de Dentro uma padaria na qual quase todos os dias, tocatas e cantigas eram entoadas por grupos que promoviam "grande ajuntamento" (NOTAS SUBURBANAS, 2 jun. 1883, p. 2).

As madrugadas nas ruas próximas onde Severo vivia nem sempre eram calmas. Certamente chegara ao seu conhecimento o assassinato do "preto livre João Pereira da Silva",

\footnotetext{
${ }^{11}$ A rua do Engenho de Dentro passou a se chamar no ano em que Severo revoltou-se contra Rosinda, em 1883, Lucídio Lago. Antes do término da década anotava-se a existência de 400 edificações nas principais ruas do bairro. Só na Engenho de Dentro existiam cerca de 90 moradias, entre casas térreas, chalés, lojas e sobrados. Em muitos quintais havia, além da casa principal, várias casinhas ou quartos para alugar. Afinal, as Oficinas da Estrada de Ferro Dom Pedro II trouxeram para a região, na década de 1880, centenas de operários (SERFATY, 2017).
} 
ocorrido ali na madrugada de 24 de abril, bem como as "proezas que os gatunos estavam fazendo pelo Engenho Novo, Todos os Santos e Engenho de Dentro" (OCORRÊNCIAS DAS RUAS, 24 fev. 1883, p. 2). Havia também brigas nas portas da taverna localizada na rua em que ele morava (GAZETA DE NOTÍCIAS, 4 nov. 1883, p. 2). As reclamações dos moradores também revelam que a rua não tinha água nem luz e a falta de calçamento fazia dela um imenso lamaçal quando chuvas se abatiam sobre a cidade (GAZETA DE NOTÍCIAS, 1 mar. 1884, p. 2). Uma rua onde burros doentes ainda pastavam (GAZETA DE NOTÍCIAS, 2 mar. 1884, p. 2). A vida mudara naquele território, mas não intensamente.

Naquele dia 22 de julho de 1883, Severo não mais aguentou. O réu Severo, “escravo de Rosinda Lucinda Fernandes, natural da província do Rio de Janeiro, 20 anos, solteiro, trabalhador de roça, analfabeto": era assim que os jornais o caracterizavam. Há quanto tempo estava na condição de escravo de Rosinda? Ao dizer que ele era "sua cria", deixa antever que estava ali, na casa, talvez desde a mais tenra infância. Já eram 7 horas, noite escura de inverno. Iria afinal descansar. Bastou uma nova ordem para desencadear a revolta. Recusou: não iria socar café. Uma pancada, o bambu pegou suas pernas. Nada falou. Saiu da sala, dirigiu-se ao quarto e carregou a espingarda. A fúria resumia a tragédia da sua vida.

Num primeiro momento, informa a notícia, ele confessou o crime, “com o maior cinismo". No dia do julgamento, entretanto, negou o fato. Ao ser perguntado por que, num primeiro momento tendo confessado, negava agora a autoria do crime, respondeu então "com muita firmeza": - "O delegado e o escrivão sabem ler e escrever; podiam ter escrito o que lhes parecesse" (GAZETA DE NOTÍCIAS, 14 out. 1884, p. 1).

A resposta de Severo mostra a desconfiança em relação à palavra escrita e a dúvida em relação às artimanhas dos que sabiam ler e escrever. Como ele, analfabeto, poderia ter conferido o que o delegado e o escrivão escreveram? Na delegacia ele talvez tivesse também negado o ataque, mas o delegado e o escrivão - dominando a letra escrita que fixou sua palavra - podiam ter registrado o contrário e ele não teria possibilidade de saber. Sua atitude no tribunal foi caracterizada, pelo jornal, como indiferença. "A sua atitude no tribunal era como se aquilo tudo não fosse com ele: manteve-se sempre com a mais perfeita indiferença". Diante dos elementos de acusação, "desenvolvidos brilhantemente pela promotoria", não exibiu nenhuma reação. Diante da defesa, realizada por Joaquim Caetano da Silva, defensor nomeado ex-ofício, também 
não se viu no seu rosto nenhum sinal de aprovação ou desaprovação (GAZETA DE NOTÍCIAS, 14 out. 1884 , p. 1). A indiferença interpretada pelo jornalista era, a rigor, altivez.

Severo estava preso desde 24 de julho de 1883 . Foi acusado, de acordo com o art. $1^{\circ}$ da Lei $\mathrm{n}^{\circ}$ 4, de 10 de junho de 1835: "tentativa de morte contra sua senhora". Em 11 de outubro, apresentou-se para julgamento, que foi adiado em dois dias, por não haver defensor. No dia da pronúncia da sua sentença, foram apresentados 13 outros processos: entre eles, Domingos João Fortes, acusado de "tentativa de homicídio" (GAZETA DE NOTÍCIAS, 11 out. 1884, p. 2; O PAIZ, 11 out. 1884, p. 2; JORNAL DO COMMERCIO, 14 out. 1884, p. 1). Mas havia uma diferença entre os dois, determinada pela condição de escravo de Severo: tentar matar "sua senhora" transformava seu crime, automaticamente, de tentativa de homicídio em "tentativa de morte" e com ela a indicação de que deveria ser condenado às galés perpétuas. Já Domingos seria absolvido.

O Código Criminal de 1830, no seu art. 44, estabeleceu: “A pena de galés sujeitará os réus a andarem com calceta no pé e corrente de ferro, juntos ou separados, e a empregar-se nos trabalhos da província onde tiver sido cometido o delito à disposição do governo" (RIBEIRO, 2018, p. 159). Era isso que esperava Severo mesmo antes da condenação. Seu destino já estava selado.

Em 13 de outubro de 1884, estava Severo novamente no Tribunal. Com 40 jurados, a terceira sessão do Júri foi aberta. Não tinha defensor: Joaquim Caetano da Silva foi nomeado, pelo juiz, para defendê-lo. Na sequência, nova surpresa: o presidente do júri declarou que o acusado ia ser julgado como livre, já que existia nos autos uma declaração de Rosinda em que dizia "não querer mais o réu como de sua propriedade".

Consta do processo que, na noite de 22 de julho do ano passado, o acusado armado de uma espingarda, dera um tiro contra sua senhora R. Lucinda Fernandes, que pacificamente se achava em sua casa à rua do Engenho de Dentro, na freguesia do Engenho Novo, do que resultou ficar a mesma senhora ferida gravemente. No tribunal negou o réu o fato. Pelas respostas do conselho aos quesitos foi condenado a pena de galés perpétuas (O PAIZ, 14 out. 1884, p. 2).

Joaquim Caetano da Silva, um advogado acostumado a ser nomeado ex-ofício, “protestou por um novo julgamento". Aquela causa era a de número 375 entre as que defendera 
e, segundo ele mesmo declarara no Tribunal, mais de dois terços foram de absolvições (GAZETA DE NOTÍCIAS, 14 out. 1882, p. 1).

Sorte semelhante não teve Severo. Foi, entre todos os presos defendidos por Joaquim Caetano da Silva naquele ano de 1884, o único condenado às galés perpétuas. Assim, do Tribunal voltou para a Casa de Correção da Corte para cumprir sua pena.

A pena de galés (BRASIL, 1830) ${ }^{12}$ significava a realização de trabalhos forçados realizados nas ruas, acorrentados pelos pés e pelas mãos. Os réus andavam pelas vias públicas com "calceta", uma argola de ferro presa à perna, e correntes de ferro nos braços. Podiam estar atados uns aos outros ou caminharem separadamente. As calcetas e as correntes pesavam, cada uma, 2,5 quilos.

Os galés trajavam sempre "camisa branca de algodão liso, calça e jaqueta de algodão trançado azul, barrete de lã redondo, sapatos grosso e cinturão de vaqueta encerada de três polegadas de largura e atacado com fivela" (BRASIL, 1850, não paginado). Para quando o frio chegasse, tinham uma camisa de malha de lã grossa. Todas as peças eram marcadas com o número do preso. Recebiam a cada três meses uma calça e uma camisa e todos os anos uma manta e um chapéu de palha (BRASIL, 1850).

Certamente quando chegou à Casa de Correção, Severo, tal como acontecia com todos os presos, foi "classificado, matriculado e inspecionado pelo médico". Em seguida, foi levado para o banho e teve seu cabelo raspado. Recebeu o uniforme da casa e as ordens correspondentes a um preso de sua classe, isto é, um condenado às galés perpétuas. Caminhou em direção a sua cela, sempre em silêncio. ${ }^{13}$

\section{Ferros nos pés, correntes nas mãos, silêncio e castigos}

Acordava, ao som da alvorada, às 5 e meia da manhã. Limpava a cela e fazia sua higiene. Como um galé, após o café ia para o serviço externo. O silêncio devia ser absoluto. Severo, no

\footnotetext{
${ }^{12}$ No código estavam previstas as penas: morte na forca; galés; prisão simples; prisão com trabalho; banimento; degredo; desterro; multa; suspensão de emprego e perda de emprego (para funcionários públicos); e açoites (para escravos). Lei de 16 de dezembro de 1830. Código Criminal do Império do Brasil, art. 44 e 45 , parágrafos $1^{\circ}$ e $2^{\circ}$ (BRASIL, 1830). A pena das galés seria revogada pelo Decreto 774 de 20 de setembro de 1890 (BRASIL, 1890). ${ }^{13} \mathrm{Em} 1882$, após 32 anos de funcionamento, o estabelecimento penitenciário ganhou um novo regulamento (Decreto 8.386, de 14 de janeiro de 1882). Manteve-se em relação ao regimento anterior o isolamento em células durante a noite e o trabalho durante o dia sempre sob o regime de rigoroso silêncio (ARAÚJO, 2007).
} 
trabalho nas ruas, com ferros nos pés e correntes nas mãos, sem poder parar, devia ficar sempre calado. Quebrar o silêncio levava a ser castigado, com um chicote. Se, porventura, interrompessem o silêncio ou violassem qualquer das normas a que estavam submetidos, eram imediatamente advertidos pelo guarda: "número (e enunciavam o número que encobria definitivamente o nome) silêncio" (BRASIL, 1850). ${ }^{14}$ Qual seria o número de Severo?

As punições iam do trabalho solitário e de tarefa, passavam pela alimentação restrita a pão e água, ficar fechado numa "célula obscura", passar de uma "classe mais favorecida para uma mais austera" ou enfrentar os "ferros". Havia também torturas, castigos denominados "estação" e "corpo curvado". No primeiro deveria ficar em pé, com os pés atados ao chão e os braços presos pelas costas. No corpo curvado, deveria sentar-se com as pernas dobradas, presas pelos braços atados nos pulsos e se sustentar nesta posição por uma vara enfiada por baixo dos joelhos e por cima dos braços (PESSOA, 2000, p. 111).

Muitos trabalhavam na pedreira que ficava ao lado da Casa, cuja terra foi utilizada para aterrar os pântanos da Cidade Nova. Em $1^{\circ}$ de janeiro de 1883, existiam na Casa de Detenção da Corte 395 presos, sendo 285 livres e 110 escravos. Os condenados às galés no final daquele ano eram 23 (BRASIL, 1883, p. 42). Um deles era Severo.

Naquele ano, na manhã de 14 de dezembro, mais de 300 presos, que "na noite anterior tinham tentado sublevar-se, arrombaram quase todos os cubículos, destruíram barbaramente o interior da prisão, rouparias e demais dependências centrais, procurando finalmente evadir-se, sendo obstados pelas prontas e enérgicas providências e auxílio dos escravos” (BRASIL, 1883, p. 42). No relatório, o diretor Belarmino Pessoa de Mello deixava claro que havia prisões destinadas aos escravos e que elas, situadas "um metro abaixo do nível das demais dependências", eram "úmidas, infectadas e insalubres" (BRASIL, 1883, p. 2). Severo ficava numa dessas celas. Os galés e os condenados à prisão perpétua eram, em quase sua totalidade, escravos como Severo.

\section{Caminhando para o fim}

Um mês depois da revolta de Severo que o colocou para sempre na Casa de Detenção, Rosinda Lucinda Fernandes fez publicar num jornal de grande circulação uma nota em que

\footnotetext{
${ }^{14}$ Art. 47, cap. IV. CLB. Regulamento da Casa de Correção da Corte, 1850. Decreto 678, 6 jul. 1850.
} 
agradecia aos seus parentes, pessoas da sua amizade e vizinhos, que "pessoalmente me vieram visitar, e outros que mandavam sempre saber novas do meu estado". Agradecia particularmente ao seu médico, Dr. Souza Lopes, "pela delicadeza e pontualidade com que me tratou". Na mesma nota, dizia ainda sofrer dores na coxa e perna direita, "proveniente do tiro que me deu o meu escravo Severo, na noite de 22 de julho do corrente ano". Para ela, o tiro só não fora mortal "devido à escuridão da noite" (ENGENHO NOVO, 25 ago. 1883, p. 3).

A mesma noite que, no caso do julgamento, seria lembrada como agravante do crime (perpetrar uma ação contra outro encoberto pela escuridão noturna era, no Código Penal de 1830, considerado motivo de agravo do crime), era, na argumentação de Rosinda, a razão de Severo ter errado a mira. A noite encobrira detalhes e transformara o alvo em sombras, impedindo o tiro certeiro.

Quase dois anos depois do dia em que Severo, tomado de uma fúria que resumia sua raiva diante de uma vida cruel, pegara sua espingarda e desferira um tiro contra Rosinda, uma pequena nota perdida num jornal trazia, de maneira lacônica, uma informação que dava conta de que a vida de Severo tinha chegado ao fim.

\footnotetext{
A mesa do júri foi ontem comunicada pelo juiz do $10^{\circ}$ distrito criminal que o escravo Severo, cujo julgamento por crime de tentativa de homicídio, devia também efetuar-se nesta sessão, falecera na Casa de Detenção a 27 de março próximo passado (O PAIZ, 9 abr. 1885, p. 1).
}

Seria o mesmo Severo? Tudo faz crer que sim. Afinal, ele tinha sido julgado pelo mesmo $10^{\circ}$ distrito criminal. Seu advogado tinha protestado contra a pena imposta a ele e solicitado novo julgamento. Quase dois anos se passaram. Era o tempo para que o homicídio com agravante que lhe fora imputado pudesse se transformar em "tentativa de homicídio", como está expresso na pequena nota perdida no meio a tantas outras no emaranhado de letras de um jornal que produz conexões possíveis do passado em direção ao presente.

De que Severo teria morrido? Não sabemos e talvez jamais saberemos. Afinal, nenhum historiador acha o que procura, contentando-se em interpretar o que por sorte pode vir a saltar diante de seus olhos. 


\section{Referências}

ARAÚJO, Carlos Eduardo Moreira de. Cárceres imperiais: a Casa de Correção do Rio de Janeiro. Seus detentos e o sistema prisional no Império, 1830-1861. 2009. Tese (Doutorado em História) - Programa de Pós-Graduação em História, UNICAMP, Campinas, 2009.

ARAÚJO, Carlos Eduardo Moreira de. Da casa de correção da corte ao Complexo Penitenciário da Frei Caneca: um breve histórico do sistema prisional no Rio de Janeiro, 1834-2006. Revista do Arquivo Geral da Cidade do Rio de Janeiro, Rio de Janeiro, n. 1, p. 147-161, 2007. Disponível em: http://wpro.rio.rj.gov.br/revistaagcrj/wp-content/uploads/2016/12/e01a08.pdf. Acesso em: 14 jul. 2021.

ARFUCH, Leonor. O espaço biográfico: dilemas da subjetividade contemporânea. Rio de Janeiro: EdUFERJ, 2010.

AZEVEDO, Elciene. Orfeu da Carapinha: a trajetória de Luís Gama na imperial cidade de São Paulo. Campinas: UNICAMP, 1999.

BAKHTIN, Mikhail. Estética da criação verbal. São Paulo: Martins Fontes, 1997.

BAKHTIN, Mikhail. Marxismo e filosofia da linguagem. São Paulo: Hucitec, 1982.

BAQUAQUA, Mahommah. Biografia de Mahommah Gardo Baquaqua: um nativo de Zoogoo, no interior da África. São Paulo: Uirapuru, 2017.

BARBOSA, Marialva. Escravos e mundo da comunicação. Oralidade, leitura e escrita no século XIX. Rio de Janeiro: Mauad X, 2016.

BLASSINGAME, John W. Slave testimony: Two centuries of letters, speeches, interviews and autobiographies. Baton Rouge, La.: Louisiana State Univ. Press, 1977.

BRASIL. Decreto no. 678, de 6 julho de 1850. Dá Regulamento para a Casa de Correcção do Rio de Janeiro. Legislação, Câmara dos Deputados, Brasilia, DF. Disponível em: https://www2.camara.leg.br/legin/fed/decret/1824-1899/decreto-678-6-julho-1850-560002publicacaooriginal-82510-pe.html. Acesso em: 14 jul. 2021.

BRASIL. Decreto no. 774, de 20 de setembro de 1890. Declara abolida a pena de galés, reduz a 30 annos as penas perpetuas, manda computar a prisão preventiva na execução, e estabelece a prescripção das penas. Legislação, Câmara dos Deputados, Brasilia, DF. Disponível em: https://www2.camara.leg.br/legin/fed/decret/1824-1899/decreto-774-20-setembro-1890517659-publicacaooriginal-1-pe.html. Acesso em: 16 jul. 2021.

BRASIL. Lei de 16 de dezembro de 1830. Manda executar o Codigo Criminal. Disponível em: http://www.planalto.gov.br/ccivil_03/leis/lim/lim-16-12-1830.htm. Acesso em: 14 jul. 2021. 
BRASIL. Lei $\mathrm{n}^{\circ} 4$, de 10 de junho de 1835 . Determina as penas com que devem ser punidos os escravos, que matarem, ferirem ou commetterem outra qualquer offensa physica contra seus senhores, etc.; e estabelece regras para o processo. Disponível em: https://www.planalto.gov.br/ccivil_03/leis/lim/lim4.htm. Acesso em: 14 jul. 2021.

BRASIL. Relatório do Ministério da Justiça e Negócios Interiores. Rio de Janeiro, 1883. Relatório do Chefe de Polícia da Corte, p. 42. Disponível em: https://goo.gl/sM8Egk. Acesso em: 14 jul. 2021.

BRASIL. Recenseamento do Rio de Janeiro (Districto Federal) realizado em 20 de setembro de 1906. Rio de Janeiro: Oficina da Estatística, 1907. Disponível em: https://archive.org/details/recenseamentodo00bragoog/page/n18/mode/2up. Acesso em: 14 jul. 1821.

DAVIS, Natalie. Nas margens: três mulheres do século XVII. São Paulo: Cia das Letras, 1997.

DAVIS, Natalie. O retorno de Martin Guerre. Rio de Janeiro: Paz e Terra, 1987.

DIÁRIO DE NOTÍCIAS, Rio de Janeiro, p. 2, 2 jun. 1886.

ENGENHO NOVO. Gazeta de Notícias, Rio de Janeiro, p. 3, 25 ago. 1883.

FARIAS, Juliana Barreto. De escrava a Dona: a trajetória da africana mina Emília Soares do Patrocínio no Rio de Janeiro do século XIX. Locus: revista de história, Juiz de Fora, v. 18, n. 2, p. 13-40, 2013. Disponível em: https://periodicos.ufjf.br/index.php/locus/article/view/20607. Acesso em: 15 jul. 2021.

FARIAS, Juliana Barreto. Mercados Minas: africanos ocidentais na Praça do Mercado do Rio de Janeiro (1830-1890). 2012. Tese (Doutorado em História Social) - Programa de PósGraduação em História, USP, São Paulo, 2012.

FRANK, Zephyr L. Dutra's world: wealth and family in nineteenth-century Rio de Janeiro. Albuquerque: Universidade de New Mexico, 2004.

FURTADO, Júnia Ferreira. Chica da Silva e o contador dos diamantes: o outro lado do mito. São Paulo: Cia das Letras, 2003.

GATES, Henry Louis. The Slave's Narrative. Oxford/New York: Oxford Univ. Press, 1985.

GAZETA DE NOTÍCIAS, Rio de Janeiro, p. 5, 9 jan. 1880.

GAZETA DE NOTÍCIAS, Rio de Janeiro, p. 1, 26 fev. 1880.

GAZETA DE NOTÍCIAS, Rio de Janeiro, p. 1, 14 out. 1882. 
GAZETA DE NOTÍCIAS, Rio de Janeiro, p. 1, 1 fev. 1883.

GAZETA DE NOTÍCIAS, Rio de Janeiro, p. 1, 24 fev. 1883.

GAZETA DE NOTÍCIAS, Rio de Janeiro, p. 3, 6 jun. 1883.

GAZETA DE NOTÍCIAS, Rio de Janeiro, p. 1, 24 jul. 1883.

GAZETA DE NOTÍCIAS, Rio de Janeiro, p. 2, 4 nov. 1883.

GAZETA DE NOTÍCIAS, Rio de Janeiro, p. 2, 1 mar. 1884.

GAZETA DE NOTÍCIAS, Rio de Janeiro, p. 2, 2 mar. 1884.

GAZETA DE NOTÍCIAS, Rio de Janeiro, p. 1, 14 out. 1884.

GAZETA DE NOTÍCIAS, Rio de Janeiro, p. 2, 11 out. 1884.

GAZETA SUBURBANA, Rio de Janeiro, p.1, 15 dez. 1883.

GINZBURG, C. O queijo e os vermes. São Paulo: Cia das Letras, 1987.

GÓES, José Roberto; FLORENTINO, Manolo. Aspectos da comunidade islamita negra do Rio de janeiro no século XIX. Trashumante, Revista Americana de História Social, Medelin, n. 10, p 8-30, jul./dez. $2017 . \quad$ Disponível em: https://www.redalyc.org/journal/4556/455656700002/html/. Acesso em: 20 jul. 2021.

GRAHAM, Sandra L. Ser mina no Rio de Janeiro do século XIX. África/Ásia, Salvador, n. 45, p. 35-65, 2012.

GRAHAM, Sandra L. Caetana diz não: histórias de mulheres da sociedade escravista brasileira. São Paulo: Cia das Letras, 2005.

HELLER, Agnes. Uma teoria da história. Rio de Janeiro: Civilização Brasileira, 1993.

JORNAL DO COMMERCIO, Rio de Janeiro, p.1, 19 abr. 1878.

JORNAL DO COMMERCIO, Rio de Janeiro, p. 1, 14 out. 1884.

LEJEUNE, Philippe. O pacto autobiográfico. Belo Horizonte: UFMG, 2008.

LOVEJOY, Paul E.. Identidade e miragem de etnicidade: a jornada de Mahomman Gardo Baquaqua para as Américas. Afro-Ásia, Salvador, v. 27, p. 9-39, 2002. Disponível em: https://www.redalyc.org/pdf/770/77002701.pdf. Acesso em: 14 jul.2021. 
MACHADO, Maria Helena. Corpo, gênero e identidade no limiar da Abolição: a história de Benedicta Maria Albina da Ilha ou Ovídia, escrava (sudeste, 1880). Afro-Ásia, Salvador, v. 42, p. 157-193, 2010. Disponível em: https://www.redalyc.org/articulo.oa?id=77020008006. Acesso em: 14 jul. 2021.

MOREIRA, Paulo Staudt. "Aceite a benção e um apertado abraço de sua carinhosa mãe": escravidão, diásporas e a perenidade dos laços familiares (Porto Alegre, Salvador, século XIX). Afro-Ásia, Salvador, v. 62, p. 98-148, 2020. Disponível em: https://periodicos.ufba.br/index.php/afroasia/article/view/35608/24183. Acesso em: 22 jul. 2021.

NOTAS SUBURBANAS. Diário de Notícias, Rio de Janeiro, p. 2, 2 jun. 1883.

OCORRÊNCIAS DAS RUAS. Gazeta de Notícias, Rio de Janeiro, p. 1, 24 jul. 1883.

OCORRÊNCIAS DAS RUAS. Gazeta de Notícias, Rio de Janeiro, p. 2, 24 fev. 1883.

O CRIME do escravo Severo. Gazeta de Notícias, Rio de Janeiro, p. 1, 14 out. 1884.

O PAIZ, Rio de Janeiro, p. 2, 14 out. 1882.

O PAIZ, Rio de Janeiro, p. 2, 11 out. 1884.

O PAIZ, Rio de Janeiro, p. 1, 9 abr. 1885.

PESSOA, Gláucia Tomaz de Aquino. Trabalho e resistência na penitenciária da Corte, 18501876. 2000. Dissertação (Mestrado em História) - Programa de Pós-Graduação em História, UFF, Niterói, 2000.

PIROLA, Ricardo Figueiredo. Desafios e estratégias na construção de biografias de escravos: o caso dos rebeldes envolvidos no plano de insurreição de Campinas (1832). Resgate, Campinas, SP, v. 23, n. 29, p. 5-14, jan./jun. 2015. Disponível em: https://periodicos.sbu.unicamp.br/ojs/index.php/resgate/article/view/8645787. Acesso em: 13 jul. 2021.

PLANTA da cidade do Rio de Janeiro e de uma parte dos subúrbios. Rio de Janeiro: Laemmert \& Cia., 1885. Disponível em: http://www2.senado.leg.br/bdsf/handle/id/242531. Acesso em: 14 jul. 2021.

RAWICK, George P. (edited). The American slave: a composite autobiography. Washington: Library of Congress, 1972. Disponível em: https://www.si.edu/object/siris_sil_11061. Acesso em: 14 jul. 2021. 
REIS, João José; GOMES, Flávio dos Santos; CARVALHO, Marcos. O alufá Rufino: tráfico, escravidão e liberdade no atlântico (1822-1853). São Paulo: Cia das Letras, 2010.

REIS, João José. Domingos Sodré um sacerdote africano. São Paulo: Cia das Letras, 2008.

RIBEIRO, João Luiz. Os galés perpétuas da Galeria de Condenados na Casa de Correção da Corte Imperial do Rio de Janeiro. Revista do IHGB, Rio de Janeiro, a. 179, n. 476, p. 157-196, jan./abr. 2018.

RICOEUR, Paul. A memória, a história e o esquecimento. Campinas, SP: UNICAMP, 2008.

RICOEUR, Paul. Sí mismo como outro. Madrid: Siglo XXI, 1996.

SACRAMENTO, Igor. Nos tempos de Dias Gomes: a trajetória de um intelectual comunista nas tramas comunicacionais. Tese (Doutorado em Comunicação) - Programa de Pós-Graduação em Comunicação e Cultura, UFRJ, Rio de Janeiro, 2012.

SERFATY, Elaina R. Cirilo. Pelo trem dos subúrbios: disputas e solidariedades na ocupação do Engenho de Dentro (1870-1906). Dissertação (Mestrado em História) - Programa de PósGraduação em História Social da Cultura, PUC, Rio de Janeiro, 2017.

SILVA, Alexandra Lima da. Folhas de ébano: (auto)biografias de escravizados e ensino de história. Revista História Hoje, v. 7, n. 14, p. 263-284, 2018. Disponível em: https://rhhj.anpuh.org/RHHJ/article/view/411. Acesso em: 14 jul. 2021.

SILVA, Eduardo. Dom Obá II D África, o Príncipe do Povo. São Paulo: Cia das Letras, 1997.

SODRÉ, Muniz. A ciência do comum. Notas sobre o método comunicacional. Petrópolis: Vozes, 2014.

STARLING, Marlon Wilson. The slave narrative: its place in american literary history. New York: New York University, 1949.

SWEET, James H. Domingos Álvares: african healing, and the intelectual history of the Atlantic World. Chapel Hill: The University of North Carolina Press, 2011.

XAVIER, Regina Célia. Religiosidade e escravidão, século XIX: mestre Tito. Porto Alegre: UFRGS, 2008.

XAVIER, Regina Célia. Biografando outros sujeitos, valorizando outra história: estudos sobre a experiência dos escravos. In: SCHMIDT, Benito Bisso (org.). O biográfico: perspectivas interdisciplinares. Santa Cruz do Sul, RS: UNISC, 2000.

YETMAN, Norman R. Ex-Slaves Interviews and the Historiography of Slavery. American Quarterly 36, no. 2, 1984, p. 181-210. 
Autora convidada. 